\title{
A EXPERIÊNCIA DE UM CURSO SOBRE SAÚDE DO TRABALHADOR EM UMA PERSPECTIVA AMPLIADA PARA ESTUDANTES DE UM CURSO TÉCNICO INTEGRADO AO ENSINO MÉDIO
}

\author{
Almir Ferreira Luz Junior*; Pollyana dos Santos \\ *E-mail: almir.junior@ifes.edu.br \\ Instituto Federal de Educação, Ciência e Tecnologia do Espírito Santo \\ DOI: $10.15628 /$ rbept.2020.9596
}

Artigo submetido em fev/2020 e aceito em abr/2020

\begin{abstract}
RESUMO
Esse trabalho relata a experiência de realização de um curso com a temática saúde do trabalhador sob uma perspectiva ampliada. Esse curso foi oferecido para alunos do curso técnico integrado em Química do Instituto Federal do Espírito Santo (IFES), campusAracruz e, foi orientado pelo uso da técnica da Aprendizagem por Projetos. Foi desenvolvido com encontros presenciais com vistas à compreensão dos conceitos necessários e, com uma pesquisa de campo. Ao final, os alunos entregaram os resultados dessa pesquisa por meio de uma apresentação em um evento do campus. Essa experiência demonstrou que a metodologia utilizada permitiu que os alunos apreendessem aspectos da realidade que segundo eles não poderiam apreender somente com as aulas teóricas.
\end{abstract}

Palavras-Chave: Educação Profissional. Ensino Médio. Saúde. Trabalho.

\section{THE EXPERIENCE OF A COURSE ON WORKERS HEALTH IN AN EXPANDED PERSPECTIVE FOR STUDENTS IN A TECHNICAL COURSE INTEGRATED TO HIGH SCHOOL}

\begin{abstract}
This work reports the experience of conducting a course with the theme of occupational health from an expanded perspective. This course was offered to students of the integrated technical course in Chemistry at the Federal Institute of Espírito Santo (IFES), Aracruz campus, and was guided by the use of the Project Learning technique. It was developed with face-to-face meetings in order to understand the necessary concepts and, with a field research. At the end, students delivered the results of this research through a presentation at a campusevent. This experience has shown that the methodology used allowed students to grasp aspects of reality that, according to them, they could not grasp only with theoretical classes.
\end{abstract}

Keywords: Professional Education. High School. Health. Labor. 


\section{INTRODUÇÃO}

Este trabalho relata a experiência de um curso de curta duração sobre o tema saúde do trabalhador sob uma perspectiva ampliada, aplicado a alunos do curso técnico em Química integrado ao ensino médio do Instituto Federal do Espírito Santo (IFES), campusAracruz. Esse curso faz parte de uma pesquisa ${ }^{1}$ mais ampla que versa sobre a contribuição dessa perspectiva ampliada para a formação profissional e tecnológica integrada ao ensino médio e, se tornará um produto educacional do tipo sequência didática.

A temática de desenvolvimento do curso se torna relevante na medida em que se observa um processo de precarização das relações de trabalho, ocasionando o aumento das doenças ocupacionais (ANTUNES; ALVES, 2004, p. 335). E, como sujeitos em formação na educação profissional em um projeto de "travessia" rumo à formação humana integral (MOURA, 2013), se faz necessário incentivar a atuação crítica dos alunos de modo que possam compreender a vida humana como constituição de múltiplos processos sociais. Esses podem ser a referência para o currículo e dessa forma, se forem abordados em suas múltiplas dimensões, adquirem sentido não somente social, mas também cultural e ambiental. Portanto, ainda que os conteúdos sejam "de formação geral ou específica, eles são organizados visando corresponder ao pressuposto da totalidade do real como síntese de múltiplas determinações" (RAMOS, 2017, p. 32).

Por perspectiva ampliada de saúde, entendemos que, contrariamente às prescrições que visam responsabilizar o indivíduo pelo cuidado com a sua saúde (perspectiva restrita), compreende-se que aspectos mais amplos como as condições sociais, ambientais e econômicas possuem maior importância na produção de saúde das populações.

Dessa forma, esse trabalho se organiza apresentando um referencial teórico baseado no campo da Saúde Coletiva brasileira. Depois apresenta trabalhos relacionados que justificam a realização de proposta de ensino como a que se apresenta nesse trabalho. Na sequência é apresentada a proposta em si. Por fim, são apresentados os resultados e uma discussão de uma avaliação do curso realizada pelos alunos.

\section{REFERENCIAL TEÓRICO}

A concepção de saúde sob uma perspectiva ampliada que adotamos nesse trabalho diz respeito a uma proposta que surge nos movimentos de Reforma Sanitária no mundo e, que no Brasil tiveram como ponto culminante

\footnotetext{
${ }^{1}$ Essa pesquisa está sendo desenvolvida no âmbito do Programa de Pós-Graduação em Educação Profissional e Tecnológica (ProfEPT) no IFES, campusVitória. Foi autorizada pelo Comitê de Ética em Pesquisa com Seres Humanos (CEP) do IFES, em 08 de agosto de 2019.
} 
as discussões que se estabeleceram na VIII Conferência Nacional de Saúde em 1986. Esse momento ocorreu no contexto de redemocratização da sociedade brasileira, da Assembleia Nacional Constituinte que priorizou a criação e a implantação do Sistema Único de Saúde (SUS) e, no mundo do trabalho, coincide com um processo de reorganização dos processos produtivos mediante os modelos flexíveis do toyotismo.

Essa visão de saúde emerge do campo das ciências sociais, significando uma superação da medicina tradicional baseada exclusivamente no assistencialismo curativo e na prevenção de doenças. Ao invés disso, de uma perspectiva com base em determinantes e condicionantes consegue compreender a saúde como resultado das condições ambientais, sociais, econômicas que impactam no processo saúde-adoecimento da população (GOMEZ; THEDIM-COSTA, 1997).

Esse movimento está fortemente associado ao conceito de promoção da saúde que diz respeito a um conjunto de valores como vida, saúde, solidariedade, equidade, democracia, cidadania, desenvolvimento, participação, parceria, entre outros. Combina

[...] estratégias como as ações do Estado (políticas públicas saudáveis), da comunidade (reforço da ação comunitária), de indivíduos (desenvolvimento de habilidades pessoais), do sistema de saúde (reorientação do sistema de saúde) de parcerias intersetoriais (BUSS, 2009, p. 20).

Além disso, possui um forte componente internacionalista presente nos documentos e declarações de conferências que visam a compreensão dos problemas em saúde como multifatoriais e seu enfrentamento com ações e atores múltiplos, em âmbito local e global (BUSS, 2009).

Ao analisar outros autores (LUPTON, 1995; PETERSEN, 1997) Czeresnia (2009), afirma que como esse movimento da "nova saúde pública" surgiu no contexto das sociedades capitalistas neoliberais tendo como um dos eixos o fortalecimento das comunidades e grupos sociais, houve uma tendência de diminuição das políticas do Estado, delegando aos sujeitos a responsabilidade de tomarem conta de si mesmos em uma lógica de mercado. Mas ao mesmo tempo, surgiram propostas progressistas que afirmavam a necessidade de elaboração e implantação de políticas públicas intersetoriais.

Logo, a coexistência dessas diferentes perspectivas (as que responsabilizam o Estado e aquelas que "empoderam" o indivíduo), tem contribuído para a criação de desafios na operacionalização da promoção da saúde, especialmente por causa da não distinção clara entre estratégias de promoção das práticas tradicionalmente prevencionistas (CZERESNIA, 2009).

Faz-se então necessário fazer a distinção clara entre o que entendemos como promoção da saúde e prevenção de doenças. Essa diz respeito a ações orientadas 
[...] a evitar o surgimento de doenças específicas, reduzindo sua incidência e prevalência nas populações. A base do discurso preventivo é o conhecimento epidemiológico moderno; seu objetivo é o controle da transmissão de doenças infecciosas e a redução dos riscos de doençasdegenerativas ou outros agravos específicos. Os projetos de prevenção e de educação em saúde estruturam-se mediante a divulgação de informação científica e de recomendações normativas de mudanças de hábitos (CZERESNIA, 2009, p. 49).

Desse modo, percebe-se uma compreensão equivocada que aproxima 0 conceito de prevenção com as perspectivas de promoção da saúde que a entendem como a mera educação em saúde visando a autonomia do sujeito. Ao seguir essa lógica, conclui-se que por meio de atividades educativas, o indivíduo estaria apto a cuidar de si mesmo.

Trata-se então, segundo a autora, da necessidade de construção da consciência sobre esse limite entre prevenção e promoção, de modo que isso estaria na base das "mudanças radicais na prática de saúde" (CZERESNIA, 2009 , p. 44). A questão que se impõe é que o modelo progressista proposto para a promoção de saúde é mais amplo que o da prevenção de doenças porque não se trata de medidas para o combate de uma só doença, de orientações para se evitar o contágio de doenças infecciosas, a aquisição de agravos crônico-degenerativos ou a ocorrência de acidentes de trabalho. Antes disso, o que se busca é aumentar a saúde e o bem-estar geral.

Dessa forma, a promoção da saúde engloba a prevenção de modo que "enfatiza as condições de vida e trabalho que conformam a estrutura subjacente aos problemas de saúde, demandando uma abordagem intersetorial" (TERRIS, 1990 apud CZERESNIA, 2009).

Um importante modelo sobre Determinantes Sociais de Saúde (DSS) foi elaborado por Dahlgreen e Whitehead (1991) (FIGURA 1) e estabelece de forma esquemática os fatores de maior impacto na saúde humana, demonstrando que os determinantes de saúde são exteriores ao sistema de tratamento. Na parte mais proximal do modelo encontram-se as condições individuais e hereditárias que poderiam influenciar na saúde individual. Logo depois em direção à extremidade estão os fatores de risco relacionados ao estilo de vida e hábitos dos indivíduos, como inatividade física, tabagismo, uso e abuso de álcool e drogas etc. Estes se encontram no limiar dos fatores individuais e os DSS. Em seguida, encontram-se os fatores intermediários que dizem respeito às redes sociais e comunitárias de apoio. Na sequência, estão os fatores de condições de vida e de trabalho, como disponibilidade de alimento, saneamento, habitação, e aquilo que nos interessa nesse trabalho que são as condições de trabalho e o desemprego. E por fim, não menos importantes e que influenciam todos os outros, estão os determinantes macrossociais e econômicos que muitas vezes extrapolam as barreiras nacionais e tem relação direta com o modo de produção global (CNDSS, 2008 apud SOBRAL; FREITAS, 2010). 
Nesse contexto da nova saúde pública, emerge também o campo da Saúde do Trabalhador em uma perspectiva que adota o conceito de processo de trabalho como categoria fundamental para se compreender o adoecimento do trabalhador, baseando-se nas relações sociais e históricas estabelecidas entre capital e trabalho. É um contraponto à perspectiva hegemônica da prevenção no ambiente de trabalho adotada no Brasil e baseada na Saúde Ocupacional. Esta possui o

[...] paradigma da causalidade dos agravos à saúde dá-se pela precedência das condições de trabalho, numa visão a-histórica e descontextualizada das relações econômicas, político-ideológicas e sociais que influem nos nexos entre trabalho e saúde-doença...A abordagem das relações trabalho e saúde-doença parte da ideia cartesiana do corpo como máquina, o qual expõe-se a agentes/fatores de risco. Assim, as consequências do trabalho para a saúde são resultado da interação do corpo (hospedeiro) com agentes/fatores (físicos, químicos, biológicos, mecânicos), existentes no meio (ambiente) de trabalho, que mantêm uma relação de externalidade aos trabalhadores. O trabalho é apreendido pelas características empiricamente detectáveis mediante instrumentos das ciências físicas e biológicas. Aqui os "limites de tolerância" e "limites biológicos de exposição", emprestados da higiene industrial e toxicologia, balizam a intervenção na realidade laboral, buscando "adaptar" ambiente e condições de trabalho a parâmetros preconizados para a média dos trabalhadores normais quanto à suscetibilidade individual aos agentes/fatores. Em consequência dessa compreensão, o controle da saúde preconizado pela Saúde Ocupacional resume-se à estratégia de adequar o ambiente de trabalho ao homem e cada homem ao seu trabalho (LACAZ, 2007, p. 759).

Ao contrário, como nos afirma Gomez, Vasconcellos e Machado (2018), a Saúde do Trabalhador é um campo que tem como marcos referenciais, os da Saúde Coletiva - promoção, prevenção e vigilância. Por meio da ação interdisciplinar, multiprofissional e de articulação interinstitucional, procura intervir nas relações de trabalho que provocam doenças e agravos. E isso diz respeito especialmente à garantia de direitos ou mitigação de sua perda na sociedade neoliberal. 
Figura 1 - Modelo de Dahlgren e Whitehead (1991) sobre de Determinantes Sociais de Saúde

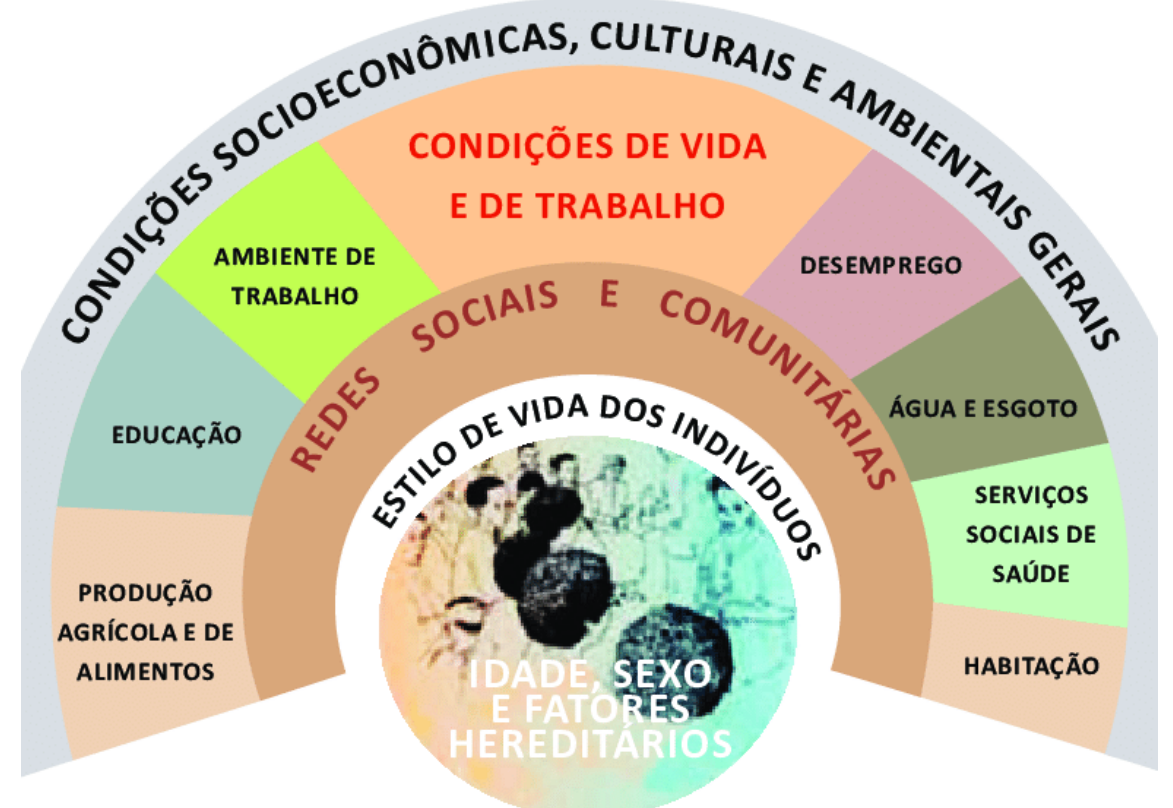

Fonte: Relatório da Comissão Nacional de Determinantes Sociais da Saúde (PELEGRINI FILHO, 2008).

Assim, numa perspectiva ampliada importa compreender como os processos de trabalho impactam na saúde do trabalhador, por meio da apreensão não do medido e do quantificado, mas sim do não mensurável como as pressões por resultados e a insegurança das relações contratuais no mercado flexibilizado, que geram e têm aumentado significativamente os agravos em saúde mental. Sendo assim, uma perspectiva reducionista não consegue ser capaz de lidar com todos os demais aspectos, alguns privados, nas quais o capital não abre oportunidade de negociação (CARDOSO, 2015).

Como forma de exemplificar o que foi abordado acima, podemos citar um estudo (CARDOSO, 2015) que tratou da experiência real vivenciada por uma profissional que enfrentava recorrentes problemas de saúde mental e física. Esse estudo demonstrou que apesar de ter emprego formal, ambiente de trabalho fisicamente confortável e ganhar acima da média, as pressões por resultados e a cobrança em horários de descanso deterioraram a sua saúde. Ou seja, ainda que em um contexto "privilegiado", ocorre precarização do trabalho. Foi exatamente aquilo que não é visível e não é mensurado que causou o adoecimento. Nas palavras da autora, 


\begin{abstract}
fazem ou raramente fazem parte da negociação com os trabalhadores, sendo definidas quase unicamente pelo capital. Por isso mesmo, ainda menos visíveis são as implicações dessas mudanças para a vida e a saúde dos trabalhadores, tanto dentro como fora do local de trabalho. Crescem e diversificam-se as formas de sofrimento e as doenças ligadas ao exercício do trabalho: fadiga generalizada, dores musculares, estresse, ansiedade, angústia, depressão, medo, esgotamento profissional (síndrome de Burnout), síndrome do pânico, ler/Dort e problemas cardíacos (ASKENAZY, 2005; DAL ROSSO, 2006; DAVEZIES, 2001; GOLLAC, 2005; SELIGMANN-SILVA, 2011; CARDOSO, 2013 apud CARDOSO, 2015).
\end{abstract}

Ainda assim, o que se propõe não é o abandono dos preceitos da Saúde Ocupacional, baseada no positivismo científico e no prevencionismo. Como afirma Caponi (2009, p. 64), "estes conhecimentos que consideram o corpo como objeto são aliados e não inimigos de uma compreensão mais ampla do conceito de saúde". Do mesmo modo que a prevenção de doenças está contida na promoção da saúde, compreendemos que a prevenção no contexto do trabalho deve estar inserida numa perspectiva mais ampliada que considera o processo de trabalho no atual modo de produção.

\title{
3 TRABALHOS RELACIONADOS
}

Os estudos apresentados nesse tópico (MARTINS; SANTOS; EL-HANI, 2016; OLIVEIRA et al, 2017; PAIVA et al, 2017; SOUSA; GUIMARÃES; AMANTES, 2019) têm a finalidade de justificar o desenvolvimento da experiência apresentada nesse trabalho.

Apresentamos inicialmente um estudo de revisão sistemática dos documentos nacionais oficiais de organização curricular para a área de Ciências da Natureza. Esse estudo demonstrou que um conceito mais amplo de saúde é pouco explorado nos documentos. Ao contrário, aparecem noções fortemente relacionadas ao conhecimento do corpo humano e aos comportamentos saudáveis, aos cuidados pessoais e aos valores ligados a autonomia e ao protagonismo (SOUSA; GUIMARÃES; AMANTES, 2019).

Também destacamos um estudo que trata da forma como o tema saúde é abordado em um livro didático de Biologia amplamente utilizado no Ensino Médio. Esse estudo demonstrou que predomina uma abordagem biomédica, e raramente se discute uma visão sociopolítica (MARTINS; SANTOS; EL-HANI, 2016).

Também utilizamos estudos de revisão sistemática que demonstraram a necessidade tanto de desenvolvimento de pesquisas na temática por meio de relatos de experiência, quanto da inclusão do tema saúde sob uma perspectiva ampliada nos currículos escolares.

Dessa forma, o trabalho de Oliveira et al (2017) é uma revisão 
sistemática de artigos que trata sobre a forma como a temática saúde é abordada em relatos de experiências sobre as aulas de educação física. De acordo com os critérios de pesquisa, esse estudo encontrou 9 artigos em um total de 23 periódicos da área selecionados. Concluiu sobre a necessidade de mais relatos sobre a saúde em uma perspectiva ampliada que "abarque outras possibilidades de compreensão do fenômeno" para além de uma perspectiva baseada no biologicismo.

Outro estudo (PAIVA et al, 2017), analisou como a temática saúde está inserida no currículo da educação física em documentos das secretarias estaduais de educação do nordeste brasileiro. Constatou que as propostas demonstram inconsistências no trato de aspectos da saúde com base na Saúde Coletiva, sendo necessárias maiores aproximações com uma visão de saúde mais ampliada, dado que predominam aspectos anátomo-fisiológicos no trato da atividade física.

Dessa forma, este trabalho se justifica por três aspectos: primeiro, pela necessidade do desenvolvimento de mais trabalhos científicos que abordem relatos de experiência sobre a saúde em uma perspectiva ampliada (OLIVEIRA et al, 2017); em segundo lugar, por haver incongruências em documentos institucionais escolares sobre o trato dessa temática (PAIVA et al, 2017); por fim, porque o desenvolvimento de uma perspectiva ampliada de saúde é "também um modo crítico de estabelecer relação com a saúde, já que segundo Almeida, Oliveira e Bracht (2016), o modelo biomédico de trato com a saúde já não é capaz de levar a compreensão desse fenômeno em toda a sua complexidade.

\section{A EXPERIÊNCIA DA REALIZAÇÃO DE UM CURSO SOBRE SAÚDE DO TRABALHADOR EM UMA PERSPECTIVA AMPLIADA}

Como citado anteriormente, o contexto de realização do curso é o desenvolvimento de uma pesquisa mais ampla que visa analisar a contribuição dos conhecimentos em saúde sob uma perspectiva ampliada para alunos em formação profissional e tecnológica. Essa pesquisa se aproxima da investigação participante, orientada pela obra de Brandão (2006). Dessa forma, o curso foi pensado levando em conta a necessidade de aproximação com esse grupo de alunos de forma a incentivar "o ser humano mais instruído e mais sábio, mas igualmente mais justo, livre, crítico, criativo, participativo, corresponsável e solidário" (BRANDÂO, 2006, p. 21).

A organização do curso iniciou com a realização de uma enquete com os alunos das turmas do $2^{\circ}$ ano do Curso Técnico Integrado em Química, por meio de um formulário eletrônico na rede mundial de computadores, de forma a saber se eles se interessavam em participar de um curso com a temática da saúde do trabalhador. A pergunta foi se possuíam interesse em participar de um curso sobre a Saúde do Trabalhador, afirmando que o curso seria realizado às segundas-feiras, no período vespertino (contra turno). O formulário obteve 
uma taxa de resposta de $33 \%$, sendo que do total de alunos que responderam, $27,5 \%$ afirmaram que gostariam de participar de um curso sobre a temática.

Esta enquete foi direcionada a essas turmas porque nesse período de sua formação estão realizando a disciplina Qualidade, Segurança, Meio Ambiente e Saúde que trata de aspectos relativos à saúde ocupacional. Por isso, o curso foi oferecido na modalidade de ação complementar ao ensino somente para os alunos dessas turmas, sendo que a proposta foi submetida à Pró Reitoria de Ensino (PROEN) do IFES de acordo com o edital 01/2019 e autorizada em 23 de agosto de 2019.

O curso contou com a participação de vinte estudantes que foram incluídos por adesão voluntária. Ao realizar a inscrição com o pesquisador, caso fossem maiores de idade, deveriam receber, ler e assinar o Termo de Consentimento Livre e Esclarecido demonstrando sua voluntariedade em participar da pesquisa. Caso fossem menores de idade, deveriam receber, ler e assinar o Termo de Assentimento Livre e Esclarecido e pedir aos pais ou responsáveis que lessem e assinassem o Termo de Consentimento Livre e Esclarecido de Responsável pelo Menor de Idade.

Antes de iniciá-lo, realizou-se entrevistas com os alunos que se inscreveram e com os professores da disciplina supracitada, para aprofundar a compreensão sobre a formação humana no tema e, para elaborarmos o curso em si. Os professores entrevistados possuem formação inicial em Engenharia Civil e Engenharia Química e, ministram outras disciplinas da área técnica. As entrevistas foram gravadas com aparelho de captação e gravação de áudio e depois disso foram transcritas.

É importante pontuar que antes de seu início o curso já possuía uma base de temas que julgávamos relevantes para o aluno. Entre estes estavam: o conceito tradicional e ampliado de saúde, medicina prevencionista e Saúde do Trabalhador, uma visita técnica a uma empresa da região, entrevistas com membros dos sindicatos e/ou com os trabalhadores, entre outros. No entanto, foi possível que outros temas considerados relevantes pelos estudantes (e que se inserissem na temática saúde do trabalhador) surgissem e ganhassem espaço de igual relevância no conteúdo do curso.

Assim, estruturou-se em encontros semanais presenciais no espaço do campusAracruz e, em pesquisas de campo realizadas pelos alunos que ocorreram em uma empresa do município de Aracruz e em um sindicato de trabalhadores existentes na cidade. Foi executado com uma carga horária total de vinte horas, com dez encontros de duas horas cada, somando-se os momentos no campuse em pesquisa de campo.

A opção didática foi a utilização da metodologia ativa de ensinoaprendizagem de Aprendizagem por Projetos. Esta técnica tem como objetivo a formulação de soluções para problemas e a criação de produtos que tenham impacto na vida fora da sala de aula. Por meio dos projetos são desenvolvidas habilidades como senso crítico, criatividade e a descoberta de várias maneiras de se realizar uma tarefa. Uma característica fundamental é a necessidade de que ao final do processo seja entregue um produto que não necessita ser um 
objeto concreto. Podem ser entregues ideias, teorias, campanhas educativas, entre outros (MORAN, 2018).

Sendo assim, nesse curso desenvolvemos um projeto de pesquisa e entregamos como produto da pesquisa dos alunos, os resultados que foram apresentados na Semana de Ciência e Tecnologia do campus Aracruz do IFES, em novembro de 2019.

A finalidade dos encontros presenciais foi o desenvolvimento conceitual dos alunos sobre a temática e a elaboração do material de investigação para a pesquisa de campo que realizaram. De outra forma, a pesquisa de campo teve como finalidade a apropriação prática dos conceitos apresentados com vistas a uma maior sistematização do conhecimento. O Quadro 1 demonstra os encontros do curso por tema e as atividades desenvolvidas.

Optamos pela divisão em unidades temáticas de forma a orientar a organização das atividades de desenvolvimento. Na Unidade 1 foram realizados momentos teóricos de apresentação de temas que serviriam de base para a pesquisa de campo.

No primeiro encontro, realizamos orientações aos alunos sobre a organização do curso e da expectativa para o final com a apresentação do trabalho no evento. Além disso, por meio de uma exposição dialogada, apresentamos os conceitos principais de saúde, promoção e prevenção e os determinantes sociais em saúde.

Apresentamos uma discussão no segundo encontro sobre como as mudanças atuais no capitalismo têm impactado a saúde do trabalhador e da trabalhadora de maneira global. Fenômenos como a desindustrialização, o capitalismo financeiro e a precarização do trabalho foram o foco desse encontro.

No terceiro encontro abordamos as mudanças na realidade brasileira provocada pela mudança na legislação brasileira, especialmente a Reforma Trabalhista ${ }^{2}$.

Iniciamos a Unidade 2 e procuramos desenvolver os conceitos básicos de pesquisa científica. Portanto, no quarto e no quinto encontros desenvolvemos o problema de pesquisa, os objetivos e os instrumentos, conjuntamente com os estudantes. Além disso, nós os preparamos para a fase posterior que seria a pesquisa de campo.

\footnotetext{
${ }^{2}$ Nesse encontro contamos com a presença do Sr. Carlos Henrique Campagnaro Recla, Auditor-Fiscal do Trabalho, que ministrou uma aula com o tema: Reforma Trabalhista e impactos na saúde do trabalhador.
} 
Quadro 1 - Encontros do curso

\begin{tabular}{|c|c|}
\hline \multicolumn{2}{|l|}{ Encontro } \\
\hline \multicolumn{2}{|r|}{ Unidade 1 - Desenvolvimento conceitual } \\
\hline 1 & $\begin{array}{l}\text { Abertura do curso: conceitos básicos de saúde e seus } \\
\text { determinantes. Relações com a saúde do trabalhador. }\end{array}$ \\
\hline 2 & $\begin{array}{l}\text { As mudanças no mundo do trabalho e a saúde do trabalhador } \\
\text { (parte 1). Desindustrialização, financeirização e precarização do } \\
\text { trabalho. }\end{array}$ \\
\hline 3 & $\begin{array}{l}\text { As mudanças no mundo do trabalho e a saúde do trabalhador } \\
\text { (parte 2). A realidade brasileira com as mudanças na legislação } \\
\text { trabalhista. }\end{array}$ \\
\hline \multicolumn{2}{|r|}{ Unidade 2 - Planejamento da Pesquisa de Campo } \\
\hline 4 & $\begin{array}{l}\text { Noções de pesquisa de campo. Desenvolvimento do problema de } \\
\text { pesquisa, dos objetivos e escolha de instrumentos para a coleta } \\
\text { de dados. }\end{array}$ \\
\hline 5 & Produção de material de coleta de dados \\
\hline \multicolumn{2}{|r|}{ Unidade 3 - Pesquisa de campo, tratamento de dados e apresentação } \\
\hline 6 & Visita a uma empresa da região. \\
\hline 7 & Visita a um sindicato. \\
\hline 8 & Tratamento dos dados. \\
\hline 9 & Tratamento de dados e produção de pôster para a apresentação. \\
\hline 10 & Apresentação na Semana Nacional de Ciência e Tecnologia 2019. \\
\hline
\end{tabular}

Fonte: Os autores (2019).

Após isso, realizamos a pesquisa de campo, sendo que no sexto encontro fomos a uma empresa da região e entrevistamos a técnica em segurança do trabalho (FIGURA 2). No sétimo encontro visitamos um sindicato local e entrevistamos o seu presidente. 
Figura 2 - Placa de orientação aos trabalhadores sobre o uso de equipamento de segurança na empresa visitada

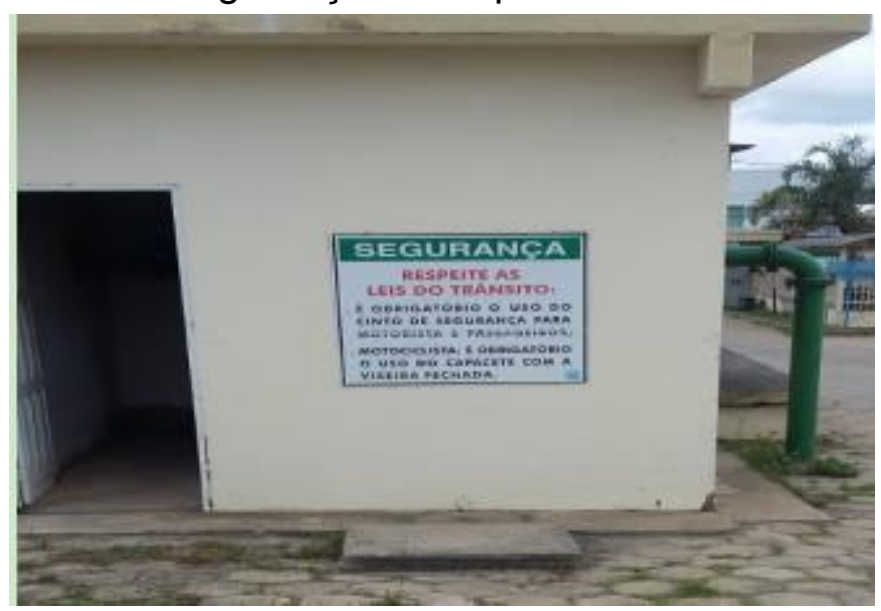

Fonte: Os autores (2019).

Figura 3 - Pôster produzido pelo grupo para apresentação na Semana Nacional de Ciência e Tecnologia do campus Aracruz

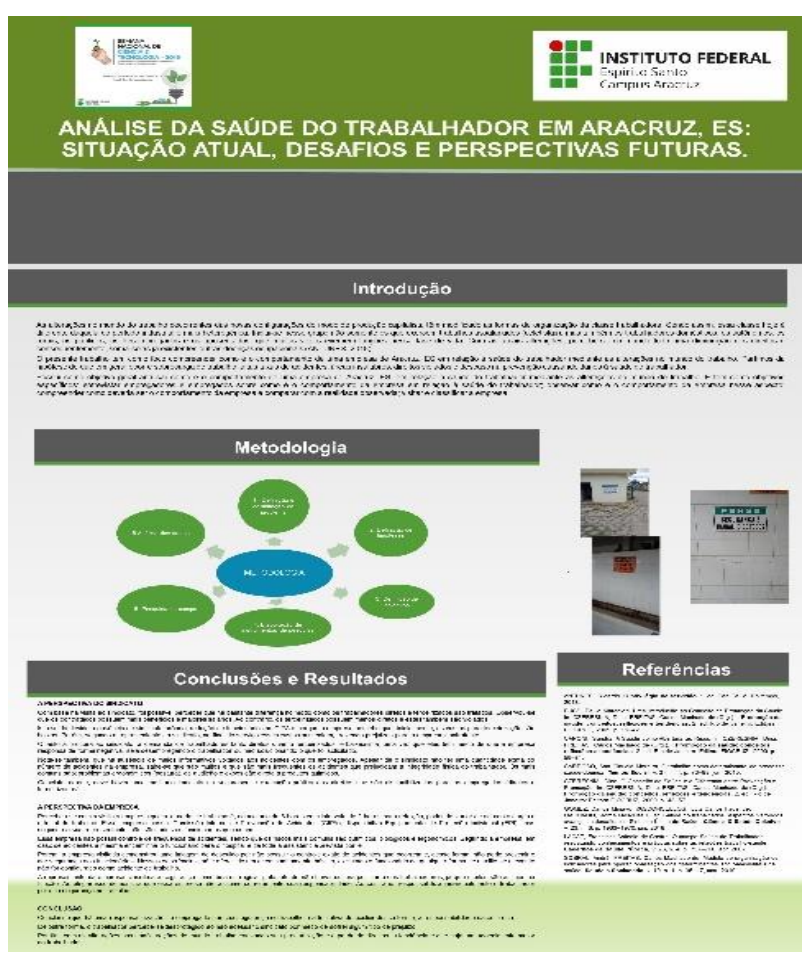

Fonte: Os autores e seus alunos (2019). 
De posse dos dados coletados, os alunos realizaram o tratamento destes e prepararam a apresentação no oitavo, nono e décimo encontros. Conforme demonstrado na Figura 3 , os alunos produziram um pôster e elegeram três colegas para apresentarem o trabalho no evento.

\section{RESULTADOS E DISCUSSÕES}

Utilizamos para a análise da experiência com o curso, a produção dos alunos com a pesquisa e uma avaliação realizada próximo ao final do curso.

Sobre a pesquisa realizada pelos alunos, nosso intuito era de que eles fizessem uma relação entre as mudanças no mundo do trabalho e a saúde do trabalhador. Logo, apesar dos alunos serem protagonistas nesse processo, os orientamos nesse sentido. A produção dos elementos principais de pesquisa ocorreu por meio de um debate com anotações no quadro branco e está detalhada no Quadro 2.

Quadro 2 - Elementos da pesquisa produzida pelos alunos

\begin{tabular}{|c|c|}
\hline \multirow{2}{|c|}{ Elementos da pesquisa } \\
\hline Problema de pesquisa & $\begin{array}{c}\text { Como é o comportamento da empresa } \\
\text { em relação à saúde do trabalhador } \\
\text { mediante as alterações no mundo do } \\
\text { trabalho? }\end{array}$ \\
\hline Perguntas secundárias & $\begin{array}{c}\text { Quais ações a empresa faz para evitar } \\
\text { acidentes de trabalho? } \\
\text { Como são as condições de trabalho em } \\
\text { uma empresa de Aracruz, ES? } \\
\text { Os empregados percebem se os direitos } \\
\text { são violados? } \\
\text { A empresa segue as NR's? } \\
\text { Quais os riscos para a saúde do } \\
\text { trabalhador? } \\
\text { Como a empresa se comporta quando } \\
\text { ocorrem acidentes? }\end{array}$ \\
\hline Hipótese ou pressuposto inicial & $\begin{array}{c}\text { Ocorre sobrecarga de trabalho, alta taxa } \\
\text { de acidentes, área insalubres, direitos } \\
\text { violados e descaso na prevenção. }\end{array}$ \\
\hline Objetivo geral & $\begin{array}{c}\text { Analisar como é o comportamento de } \\
\text { uma empresa em Aracruz, ES, em } \\
\text { relação à saúde do trabalhador mediante } \\
\text { as alterações no mundo do trabalho. }\end{array}$ \\
\hline Objetivos específicos & \begin{tabular}{c} 
Questionar empregadores e empregados \\
\hline
\end{tabular} \\
\hline
\end{tabular}




\begin{tabular}{|l|c|}
\hline \multirow{1}{*}{$\begin{array}{c}\text { sobre como é comportamento da } \\
\text { empresa em relação à saúde do } \\
\text { trabalhador mediante as alterações no } \\
\text { mundo do trabalho. } \\
\text { Observar como é comportamento da } \\
\text { empresa em relação à saúde do } \\
\text { trabalhador mediante as alterações no } \\
\text { mundo do trabalho. } \\
\text { Entender como deveria ser o } \\
\text { comportamento da empresa e comparar } \\
\text { com a realidade percebida. } \\
\text { Visitar a empresa e o sindicato } \\
\text { Classificar a empresa. }\end{array}$} \\
\hline Uma empresa de Aracruz, ES e um \\
sindicato de representação de \\
trabalhadores localizado em Aracruz, ES.
\end{tabular}

Fonte: Os autores e seus alunos (2019).

Após o desenvolvimento dos elementos da pesquisa, passamos para a fase de produção dos instrumentos para coleta de dados que foi uma entrevista semiestruturada. A turma foi dividida em três grupos: um grupo ficou responsável pela entrevista com a representante da empresa, o outro grupo ficou responsável pela entrevista com o representante do sindicato e o último com a avaliação do curso pelos colegas.

As perguntas elaboradas pelos alunos dos grupos empresa e sindicato estão descritas no Quadro 3.

Quadro 3 - Perguntas elaboradas pelos grupos de alunos

\begin{tabular}{|c|c|}
\hline $\begin{array}{c}\text { Perguntas para a repres } \\
\text { empresa }\end{array}$ & $\begin{array}{l}\text { sindicato } \\
\text { singumias para reses }\end{array}$ \\
\hline $\begin{array}{c}\text { Qual é a postura da empresa diante } \\
\text { das NR's } 004 \text { (SESMT), 005 (CIPA) } \\
\text { e } 006 \text { (EPI)? } \\
\text { Qual a taxa anual de acidentes } \\
\text { (frequência)? E quais são os tipos } \\
\text { mais frequentes de acidentes de } \\
\text { trabalho e doenças ocupacionais? } \\
\text { Quais as ações de prevenção de } \\
\text { acidentes que a empresa toma? } \\
\text { Quais as funções são terceirizadas? } \\
\text { Como a empresa se porta diante da } \\
\text { segurança dos empregados } \\
\text { terceirizados? O tratamento é o }\end{array}$ & $\begin{array}{l}\text { Qual o fluxo de trabalhadores que } \\
\text { procuram o sindicato? Alto, médio ou } \\
\text { baixo? } \\
\text { Quais os principais motivos para os } \\
\text { trabalhadores não procurarem o } \\
\text { sindicato? Medo de perder o emprego? } \\
\text { Falta de informação? Outros? } \\
\text { Quais as condições de trabalho para os } \\
\text { terceirizados em relação aos } \\
\text { contratados diretos? (diferença nas } \\
\text { condições de trabalho entre ambos). } \\
\text { Quais os acidentes de trabalho mais } \\
\text { comuns nessa área? }\end{array}$ \\
\hline
\end{tabular}


mesmo que os demais?

Quais as alterações notadas na saúde do trabalhador a partir das atuais mudanças no mundo do trabalho?

Qual a assistência que a empresa dá quando acontece algum acidente?

Qual a Jornada de Trabalho atual? Qual o posicionamento da empresa diante da nova lei sobre o horário de almoço? E o tempo de jornada mudou?

Já houve algum processo judicial em relação à segurança e saúde do trabalhador na empresa?

Quais são os tipos de risco que o trabalho na empresa oferece ao

trabalhador na empresa?

Classifique a Segurança do trabalhador na empresa. Justifique:

$\circ$ Excelente $\circ$ Bom $\circ$ Regular

- Ruim Justificativa:
Quais as NR`s obrigatórias no setor que o sindicato atua?

Há rigidez na exigência do uso de EPI's? Alta, média ou baixa?

Como o sindicato reage ao receber denúncia?

Quais as alterações no mundo do trabalho têm afetado a saúde do trabalhador?

Das denúncias recebidas quantas são solucionadas?

Quais são as doenças ocupacionais mais comuns nesse setor de produção? De maneira geral, como vocês avaliam a Segurança nas empresas?

Qual o número de acidentes que ocorrem nesse setor anualmente?

Quais os direitos mais violados dos trabalhadores diretos?

Quais os direitos mais violados dos trabalhadores terceirizados?

Fonte: Os autores e seus alunos.

Percebe-se pelas perguntas que os alunos conseguiram desenvolver instrumentos que os permitiu apreender a realidade dos locais visitados. Percebe-se também uma busca pela relação entre as mudanças no mundo trabalho e os impactos na saúde do trabalhador.

Realizadas as visitas para as entrevistas, cada grupo foi orientado sobre como analisar as respostas passando pelos seguintes passos: primeiramente deveriam agrupar as perguntas que tratavam de temas semelhantes; depois deveriam buscar nas respostas dos grupos de perguntas, as categorias que se aproximavam; após isso, deveriam realizar uma síntese por grupos de perguntas e; por fim, deveriam realizar uma síntese final do grupo.

As sínteses dos grupos ${ }^{3}$ estão nos textos destacados abaixo.

Percebeu-se com a visita à empresa que a jornada de trabalho é, na maioria de 8 horas com intervalo de 2 horas para refeição, podendo variar de acordo com o cargo e o local de trabalho. Essa empresa possui Comissão Interna de Prevenção de Acidentes (CIPA),

\footnotetext{
${ }^{3} \mathrm{~A}$ análise das sínteses dos grupos está em andamento para a finalidade da pesquisa mais ampla.
} 
disponibiliza Equipamento de Proteção Individual (EPI), mas segundo a sua representante, não são todos os funcionários que usam. Essa empresa não possui controle de frequência de acidentes, sendo que os riscos mais comuns são químicos, biológicos e ergonômicos. Segundo a empresa, em caso de acidentes a mesma encaminha o funcionário para o hospital e dá toda a assistência prevista por lei. Porém, a empresa visitada demonstrou uma imagem de descuido por não possuir o controle exato de acidentes que ocorrem e, dessa forma, não pode prevenir e dar segurança aos funcionários. Nessas ocorrências, só é oferecido um acompanhamento básico, excluindo o funcionário de qualquer forma de auxílio se o evento não for configurado como acidente de trabalho. A representante da empresa classifica a segurança como boa ou regular pelo fato de não haver cultura por parte dos trabalhadores, já que muitos são antigos na função. Ao alegar isso demonstra que essa empresa não assume corretamente sua responsabilidade. Ao contrário, responsabiliza individualmente o trabalhador por sua segurança no trabalho (síntese do grupo que entrevistou a representante da empresa).

Baseado nas pesquisas de campo e estudos realizados em sala de aula, foi possível perceber que há bastante diferença no modo como os trabalhadores diretos e terceirizados são tratados. É visível que os contratados possuem benefícios, enquanto os terceirizados são carentes, principalmente, quanto aos seus direitos, que são poucos e, ainda, violados. Isto se dá devido à ausência de sindicato próprio, redução de funcionários na CIPA e porque a empresa percebe que, inicialmente, os custos para terceirização são baixos, porém, no final do serviço esses custos aumentam, trazendo prejuízos para a empresa contratante. Quanto ao sindicato, a demanda de trabalhadores, tanto diretos quanto terceirizados, que procuram 0 sindicato é baixíssima, uma vez que eles têm medo da empresa responder de forma negativa, seja desempregando o trabalhador ou não solucionando o que foi solicitado. Nota-se, também, que há ausência de meios informativos voltados para os empregados. Apesar de não ter uma quantidade exata do número de acidentes na empresa, sabe-se que são muitos e que são mais frequentes acidentes que prejudicam a integridade física do trabalhador. Os mais comuns são: problemas ergonômicos (postura), de audição e exposição direta à produtos químicos. Concluímos que, deve haver uma melhoria imediata na segurança e execução prática dos direitos que são disponibilizados para os empregados (diretos e terceirizados) (síntese do grupo que entrevistou o representante do sindicato).

Próximo ao final do curso os alunos responderam uma avaliação que foi elaborada por um grupo de colegas do curso. Isso se deu por meio de um formulário na internet e contou com seis perguntas abertas que eram:

1) o que você nos diria sobre a metodologia do curso?

2) o curso está atendendo as suas expectativas iniciais? Justifique.

3) os conteúdos abordados no curso te dão o conhecimento necessário para compreender a saúde do trabalhador? Justifique.

4) qual a sua opinião sobre a promoção da saúde do trabalhador dentro da empresa? 
5) em relação ao currículo do curso de Química, esse curso tem ampliado a sua visão sobre o trabalhador?

6) nos conte como está sendo sua experiência até aqui.

O grupo também realizou uma síntese que está demonstrada na sequência, mas optamos em analisar as respostas em si. Essas respostas do formulário foram agrupadas por temas das perguntas que se aproximavam e, foi realizada uma análise conjunta. Desse modo, as questões um, dois e seis buscavam compreender a experiência com o curso quanto à metodologia, expectativas e a percepção geral. As questões três e cinco tratavam dos conhecimentos desenvolvidos e compartilhados durante o curso e se esses ampliaram a perspectiva de saúde dos participantes. A quarta questão ficou separada porque dizia respeito à percepção da realidade observada por eles. Além disso, trouxemos algumas anotações do diário de campo do pesquisador.

\begin{abstract}
Através das perguntas feitas pelo grupo aos colegas, percebemos que o curso apresenta uma metodologia dinâmica e muito interessante, abordam assuntos de amplas áreas como por exemplo, as aulas de QSMS. As expectativas iniciais foram contempladas tendo apenas uma crítica que é devido à ausência de debates. $O$ curso nos auxilia no mercado de trabalho, abordando temáticas como as normas trabalhistas, direitos e deveres, legislação e das diferenças das condições de trabalho entre os países. Ao compararmos a saúde do trabalhador com o Curso de Química, vemos que eles têm muita relação pois na área de Química aprendemos a manusear produtos tóxicos com cautela, para não causar acidentes, as aulas de QSMS ampliam esses conhecimentos e nos preparam para o mercado de trabalho. Podemos concluir que a promoção da saúde do trabalhador deveria ser mais divulgada, principalmente para os funcionários valorizando sua vida e seu trabalho (síntese do grupo que formulou a avaliação do curso).
\end{abstract}

As respostas do primeiro grupo de questões demostraram uma aceitação ao curso dado que apresentaram com frequência alta o termo "muito boa", justificando especialmente o fato de terem realizado uma pesquisa de campo e não somente em sala de aula.

Acho uma excelente metodologia, visto que não é formada apenas por teorias/conceitos, mas também, é constituída por práticas/pesquisas de campo, facilitando a compreensão do mesmo (Participante do curso).

Desse modo, a escolha metodológica foi bem aceita, porque essa era uma das expectativas dos alunos antes do início. Com base nas anotações em diário de campo, relembramos de um relato em que eles se queixavam do fato de que ainda não haviam realizado uma única visita técnica desde o início do curso integrado de Química. Logo, para eles isso foi uma oportunidade. Além 
disso, as visitas que foram desenvolvidas na pesquisa de campo, se tornaram uma forma de melhor apreensão da realidade.

O segundo grupo de respostas sugere que os conhecimentos ampliaram a percepção dos alunos sobre a saúde do trabalhador visto que a resposta mais frequente esclareceu sobre o fato de que por não haver muito conteúdo, o curso permitiu que o que foi estudado pudesse ser compreendido de forma satisfatória. Além disso, mais uma vez apareceu com frequência a categoria conhecimento da realidade.

Isso nos remete ao fato de que um projeto que pretende ser uma "travessia" para a formação humana omnilateral (MOURA, 2013) por meio da integração entre mundo do trabalho e educação, não pode menosprezar atividades e vivências que permitam aos alunos a apreensão da realidade fora do espaço escolar.

As respostas à quarta questão demonstraram um aprofundamento da categoria conhecimento da realidade, visto que sabendo que a promoção da saúde nas empresas era fundamental, puderam observar que nem todas as empresas davam a mesma importância. Inclusive, com base nas anotações no diário de campo, relembramos o fato que ficou muito claro para os alunos que a empresa que visitamos responsabilizava os empregados por não terem uma cultura de prevenção.

\section{CONSIDERAÇÕES FINAIS}

A experiência relatada nesse trabalho demonstrou que 0 desenvolvimento de metodologias e eleição de conteúdos que permitam uma percepção maior da realidade por parte dos alunos, pode ser uma via para que estes apreendam melhor as contradições dos modos de vida e produção, e isso se aproxima das bases fundamentais da educação profissional e tecnológica.

Apesar do fato que os estudantes, em suas respostas, nem sempre demonstrarem uma percepção da associação entre as mudanças no mundo do trabalho e o adoecimento do trabalhador, o tema em si permite uma apropriação mais crítica por parte deles do trato com a saúde, já que é comumente abordada somente em seus aspectos individuais e físicos, sem um aprofundamento dos seus determinantes sociais. Isso se torna mais relevante na sociedade brasileira marcadamente caracterizada pelas desigualdades e pelo recente aumento da precarização do trabalho. 


\section{REFERÊNCIAS}

ALMEIDA, Ueberson Ribeiro; OLIVEIRA, Victor José Machado de; BRACHT, Valter. Educação física escolar e o trato didático-pedagógico da saúde: desafios e perspectivas. In: WACHS, Felipe; RIBEIRO ALMEIDA, Ueberson; BRANDÃO, Fabiana F. de Freitas (Orgs.). Educação Física e Saúde Coletiva Cenários, experiências e artefatos culturais. Porto Alegre: Rede Unida, 2016. p. 87-112.

ANTUNES, Ricardo; ALVES, Giovanni. As mutações no mundo do trabalho na era da mundialização do capital. Educação \& Sociedade, v. 25, n. 87, p. 335351, ago. 2004. Disponível em: http://www.scielo.br/scielo.php?pid=S0101 $73302004000200003 \&$ script=sci_arttext\&tlng=pt. Acesso em: 01 jan. 2018.

BUSS, Paulo Marchiori. Uma introdução ao Conceito de Promoção da Saúde. In: CZERESNIA, Dina; FREITAS, Carlos Machado de (Orgs.) Promoção da saúde: conceitos, reflexões e tendências. 2. ed. Rio de Janeiro: Editora FIOCRUZ, 2009. p. 19-42.

BRANDÃO, Carlos Rodrigues. Pesquisa participante e a participação da pesquisa. In: BRANDÃO, Carlos Rodrigues; STRECK, Danilo R. (Orgs.)

Pesquisa participante: a partilha do saber. Aprecida: Ideias e Letras, 2006. p. 17-54.

CAPONI, Sandra. A Saúde como Abertura ao Risco. In: CZERESNIA, Dina; FREITAS, Carlos Machado de (Orgs.) Promoção da saúde: conceitos, reflexões e tendências. 2. ed. Rio de Janeiro: Editora FIOCRUZ, 2009. p. 5981.

CARDOSO, Ana Claudia Moreira. O trabalho como determinante do processo saúde-doença. Tempo Social, v. 27, n. 1, p. 73-93, jun. 2015. Disponível em: http://www.scielo.br/scielo.php?pid=S0103-

20702015000100073\&script=sci_arttext\&tlng=pt. Acesso em: 27 nov. 2018.

CZERESNIA, Dina. O Conceito de Saúde e a Diferença entre Prevenção e Promoção. In: CZERESNIA, Dina; FREITAS, Carlos Machado de (Orgs.) Promoção da saúde: conceitos, reflexões e tendências. 2. ed. Rio de Janeiro: Editora FIOCRUZ, 2009. p. 43-57.

GOMEZ, Carlos Minayo; THEDIM-COSTA, Sonia Maria da Fonseca. A construção do campo da saúde do trabalhador: percurso e dilemas. Cadernos de Saúde Pública, v. 13, n. suppl 2, p. S21-S32, 1997. Disponível em: http://www.scielo.br/scielo.php?script=sci_arttext\&pid=S0102311X1997000600003\&lng=pt\&tlng=pt. Acesso em: 22 nov. 2018.

GOMEZ, Carlos Minayo; VASCONCELLOS, Luiz Carlos Fadel de; MACHADO, Jorge Mesquita Huet. Saúde do trabalhador: aspectos históricos, avanços e desafios no Sistema Único de Saúde. Ciência \& Saúde Coletiva, v. 23, n. 6, p. 1963-1970, jun. 2018. Disponível em: https://www.scielosp.org/article/csc/2018.v23n6/1963-1970/. Acesso em: 20 nov. 2018. 
LACAZ, Francisco Antonio de Castro. O campo Saúde do Trabalhador: resgatando conhecimentos e práticas sobre as relações trabalho-saúde.

Cadernos de Saúde Pública, v. 23, n. 4, p. 757-766, abr. 2007. Disponível em: https://www.scielosp.org/article/csp/2007.v23n4/757-766/es/. Acesso em: 21 dez. 2018.

MARTINS, Liziane; SANTOS, Girlene Silva dos; EL-HANI, Charbel Niño. Abordagens de saúde em um livro didático de biologia largamente utilizado no ensino médio brasileiro. Investigações em Ensino de Ciências, v. 17, n. 1, p. 249-283, 2016. Disponível em:

https://www.if.ufrgs.br/cref/ojs/index.php/ienci/article/view/215. Acesso em: 15 fev. 2020.

MORAN, José. Metodologias ativas para uma aprendizagem mais profunda. In: BACICH, Lilian; MORAN, José (Orgs.). Metodologias Ativas para uma

Educação Inovadora: Uma Abordagem Teórico-Prática. Porto Alegre: Penso Editora, 2018. p. 26-53.

MOURA, Dante Henrique. Ensino médio integrado: subsunção aos interesses do capital ou travessia para a formação humana integral?. Educação e

Pesquisa, v. 39, n. 3, p. 705-720, 2013. Disponível em:

http://www.scielo.br/scielo.php?pid=S1517-

97022013000300010\&script=sci_arttext. Acesso em: 01 jan. 2018.

OLIVEIRA, João Paulo et al. The constitution of school health knowledge in the context of pedagogical practice in School Physical Education. Motricidade, v. 13, n. SPE, p. 97-112, 1 set. 2017. Disponível em:

http://revistas.rcaap.pt/motricidade/article/view/12875. Acesso em: 12 out. 2018.

PAIVA, Andréa Carla de et al. Health in curricular proposals for the teaching of physical education in the Brazilian Northeast: what to teach? Motricidade, v. 13, n. SPE, p. 2-16, 1 set. 2017. Disponível em:

http://revistas.rcaap.pt/motricidade/article/view/12868. Acesso em: 12 out. 2018.

RAMOS, Marise. Ensino médio integrado: lutas históricas e resistências em tempos de regressão. In: ARAÚJO, Adilson Cesar; SILVA, Cláudio Nei Nascimento da (Orgs.) Ensino médio integrado no Brasil: fundamentos, práticas e desafios. Brasília: Editora IFB, 2017. p. 20-43.

SOBRAL, André; FREITAS, Carlos Machado de. Modelo de organização de indicadores para operacionalização dos determinantes socioambientais da saúde. Saúde e Sociedade, v. 19, n. 1, p. 35-47, mar. 2010. Disponível em: http://www.scielo.br/scielo.php?pid=S010412902010000100004\&script=sci_arttext. Acesso em: 01 mar. 2019.

SOUSA, Marta Caires; GUIMARÃES, Ana Paula Miranda; AMANTES, Amanda. A saúde nos documentos curriculares oficiais para o ensino de ciências: da lei de diretrizes e bases da educação à base nacional comum curricular. Revista Brasileira de Pesquisa em Educação em Ciências, p. 129-153, 2019. 